\title{
Prior Emergency Department Utilization as a Predictor for Severe Penetrating Trauma: A Retrospective Cohort Study
}

\author{
Alexandra CW Reitz ${ }^{1}$, Michael Goodman², Stephen R Pitts ${ }^{3}$
}

\begin{abstract}
Background: While extensive research has been conducted on healthcare utilization after severe penetrating trauma events, there is a dearth of information on healthcare utilization prior to these events. This study examined the emergency department (ED) utilization patterns to determine if prior ED visits for injury were a risk factor for severe penetrating trauma.

Materials and methods: This retrospective cohort study examined the ED visit records of 215,800 patients with 489,800 ED visits and 3,322 trauma registry patients from November 2010 to February 2015 at Grady Memorial Hospital, a large, urban hospital with a level I trauma center. Data analysis was conducted using logistic regression and Cox proportional hazard models.

Results: Among 215,800 ED patients, 224 patients with prior ED visits experienced severe penetrating trauma (as reported to the trauma registry). After adjustment for age, sex, employment, insurance, high utilization, and admission status, prior ED visits for injury were associated with severe penetrating trauma (OR 1.60, Cl 1.21-2.10, $p=0.001$ ). Cox proportional hazard models were used to estimate hazard ratios (HR) for factors associated with time to a penetrating trauma event following a patient's last ED visit. After adjusting for age, sex, employment status, admission status, high utilization, and insurance status, patients with an injury diagnosis at their last ED visit had a $\mathrm{HR}$ of $1.43(\mathrm{Cl} 1.07-1.93, p=0.016)$.

Conclusion: After adjusting for confounders, a previous ED visit for injury remained a significant risk factor for severe penetrating trauma and an elevated rate of time to penetrating trauma. These findings suggest a need for targeted violence intervention programs and improved ED injury surveillance.
\end{abstract}

Keywords: Cohort study, Emergency medicine, Injury epidemiology, Injury prevention, Penetrating injuries, Violence.

\section{Abstracto}

Introducción: se ha llevado a cabo una amplia investigación sobre la utilización de la atención médica después de eventos de trauma penetrante severo. Existe una escasez de información sobre la utilización de la atención médica antes de estos eventos. Este estudio examinó los patrones de utilización del departamento de emergencias (DE) para determinar si las visitas previas a la DE por lesiones fueron un factor de riesgo de trauma penetrante severo.

Materiales y Métodos: este estudio de cohorte retrospectivo examinó los registros de visitas al servicio de urgencias de 215,800 pacientes con 489,800 visitas al servicio de urgencias y 3,322 pacientes con registro de traumas desde noviembre de 2010 hasta febrero de 2015 en el Hospital Grady Memorial, un gran hospital urbano con un trauma de nivel I. centrar. El análisis de los datos se realizó mediante regresión logística y modelos de riesgo proporcional de Cox.

Resultados: entre 215,800 pacientes, 224 pacientes con visitas previas a lo DE experimentaron un trauma penetrante severo (como se informó en el registro de trauma). Después del ajuste por edad, sexo, empleo, seguro, alta utilización y estado de admisión, las visitas previas al servicio de urgencias por lesión se asociaron con un traumatismo penetrante grave (OR 1.60, IC 1.21-2.10, $p=0.001)$. Se utilizaron modelos de riesgo proporcional de Cox para estimar Hazard ratios (HR) para los factores asociados con el tiempo hasta un evento de trauma penetrante después de la última visita al servicio de urgencias del paciente. Después de ajustar por edad, sexo, estado laboral, estado de admisión, alta utilización y estado de seguro, los pacientes con un diagnóstico de lesión en su última visita al servicio de urgencias tuvieron un HR de 1.43 (IC 1.07-1.93, $p=0.016$ ). Conclusión: Después de ajustar los factores de confusión, una visita previa al servicio de urgencias por lesiones siguió siendo un factor de riesgo significativo para traumatismos penetrantes graves y una tasa elevada de tiempo para traumatismos penetrantes. Estos hallazgos sugieren la necesidad de programas de intervención de violencia dirigidos y una mejor vigilancia de las lesiones en DE.

Palabras clave: Epidemiología de lesiones, Estudio de cohorte, Lesiones penetrantes, Medicina de emergencia, Prevención de lesiones, Violencia. Panamerican Journal of Trauma, Critical Care \& Emergency Surgery (2019): 10.5005/jp-journals-10030-1256

\section{INTRODUCTION}

While the occurrence of firearm deaths has declined in the USA since the early 1990s, there is increasing evidence that the incidence of nonfatal firearm injuries is on the rise..$^{1-3}$ In 2015, the Centers for Disease Control and Prevention (CDC) estimated 80,000 persons experienced a firearm injury. ${ }^{4}$ Due to their frequency and severity, these injuries contribute significantly to healthcare costs. From 2010 to 2012, firearm injuries resulted in an estimated $\$ 48$ billion annually in medical and work loss costs. ${ }^{1}$

A number of individual, interpersonal, community, and societal characteristics are proven risk factors for violence. Research has
${ }^{1}$ Department of Surgery, Emory University School of Medicine, Atlanta, Georgia, USA

${ }^{2}$ Department of Epidemiology, Emory University, Atlanta, Georgia, USA

${ }^{3}$ Department of Emergency Medicine, Emory University, Atlanta, Georgia, USA

Corresponding Author: Alexandra CW Reitz, Department of Surgery, Emory University School of Medicine, Atlanta, Georgia, USA, Phone: +1 4047275800, e-mail: areitz@emory.edu

How to cite this article: Reitz ACW, Goodman M, Pitts SR. Prior Emergency Department Utilization as a Predictor for Severe Penetrating Trauma: A Retrospective Cohort Study. Panam J Trauma Crit Care Emerg Surg 2019;8(3):170-175.

(-) The Author(s). 2019 Open Access This article is distributed under the terms of the Creative Commons Attribution 4.0International License (https://creativecommons. org/licenses/by-nc/4.0/), which permits unrestricted use, distribution, and non-commercial reproduction in any medium, provided you give appropriate credit to the original author(s) and the source, provide a link to the Creative Commons license, and indicate if changes were made. The Creative Commons Public Domain Dedication waiver (http://creativecommons.org/publicdomain/zero/1.0/) applies to the data made available in this article, unless otherwise stated. 
demonstrated that these risk factors are consistent for both victims and perpetrators of interpersonal violence. ${ }^{5,6}$ Individual risk factors include male gender, substance use, and emotional distress. ${ }^{7}$ Interpersonal risk factors include exposure to a victim or perpetrator of violence and low levels of family cohesion. ${ }^{5,8-10}$ Community risk factors include residing in environments with concentrated disadvantage, drug markets, and weapon availability. ${ }^{711-13}$ On a national level, the USA remains an outlier in its rates of homicide compared with other Organisation for Economic Co-operation and Development Nations. ${ }^{4}$

Stark disparities in severe penetrating trauma exist. Rates of homicide and suicide are approximately four times higher for men than for women, and African American and American Indian or Alaskan Natives have rates of homicide that far exceed those of other races or ethnic backgrounds. ${ }^{7}$ Although certain demographic groups are at higher risk for penetrating trauma, it is critical to note that risk is not homogeneously distributed among individuals within minority populations. In communities and areas with high levels of violence, there is evidence that an exceedingly small number of individuals drive serious violence that is often concentrated in specific "hot spot" locations. . $^{5,14-19}$ There is also growing evidence that victims of firearm violence in a community often share a social network. ${ }^{20-22}$ Consequently, violence prevention in high-risk individuals can potentially disrupt a cycle of violence within a wider social network.

Severe penetrating trauma is preventable. However, one of the greatest challenges surrounding violence prevention is the lack of nonlethal violence surveillance that often precedes severe violence, such as homicide. Violence is notoriously underreported, particularly to law enforcement. ${ }^{23}$ Thus, the medical system has a unique opportunity to identify high-risk individuals and intervene with proven prevention methods. The National Network of Hospitalbased Violence Intervention Programs (HVIPs), currently has a network of thirty organizations who use evidence-based methods to prevent violence. ${ }^{24}$ Most of these programs focus on severely injured patients at high risk for trauma recidivism in urban areas with a high burden of violence. Many programs have demonstrated success. In San Francisco, a HVIP targeting victims of intentional injury who were admitted for their injuries, demonstrated a fourfold reduction in injury recidivism. ${ }^{25}$ In addition, these programs have demonstrated cost-effectiveness within hospital systems and wider cost benefits. ${ }^{26,27}$

On the basis of the success of these intervention programs, we sought to identify the characteristics of emergency department (ED) patients who could potentially benefit from a violence prevention program. Our objective was to determine which factors during antecedent ED visits were associated with subsequent severe penetrating trauma. The specific risk factors of interest in this study included prior ED visits for injury along with ED visit frequency and admission status.

\section{Materials and Methods}

Data were obtained from the electronic medical record and trauma registry for all ED visits and penetrating trauma entries at Grady Memorial Hospital, an urban, public hospital with a level I trauma center, from October 2010 to March 2015. ED visits at the same time as our outcome of interest, severe penetrating trauma, were excluded as only antecedent data were utilized in this cohort design. In addition, recidivist episodes of penetrating trauma were excluded as our study sought only antecedent ED visits.

\section{Source of support: Nil}

Conflict of interest: None

The primary outcome was defined as an entry on the trauma registry for penetrating trauma consistent with the standards set forth by the National Trauma Data Standard: Data Dictionary. ${ }^{28}$ For inclusion on the trauma registry, patients must have an injury with an International Classification of Diseases, Ninth Revision, Clinical Modification (ICD-9-CM) diagnostic code from 800 to 959.9 along with a hospital admission of at least 24 hours, a fatal event, or a transfer. External cause codes were used to assign an injury to the category penetrating trauma.

Primary diagnosis for an ED visit was assigned according to ICD-9-CM codes and relevant text entries in the primary diagnosis field. Injury exposure was defined for ICD-9-CM codes from 800 to 999.99 or if the primary reason for the visit included the text entry "injury." While some studies include only the ICD-9 codes 800-959 for injuries, for this study, a wider range of injuries such as poisoning were considered relevant.

Patients with entries on the trauma registry for penetrating trauma were matched to the ED visits using medical record numbers in order to identify ED patients with the outcome of interest. Some demographic characteristics, such as age and sex were assigned using complete fields from other ED visits. High-ED usage was defined as four or more ED visits during the study period. A fourvisit metric was chosen based on it representing the top $10 \%$ of ED utilizers included in our study. Race was not used as a variable in this study since the data obtained from the electronic medical record did not include this patient information. Including race would have had a limited impact on our study since the overwhelming majority of patients at our study site identify as African American or black.

Descriptive statistics were calculated using the total study population. Logistic regression was used to assess certain characteristic associations with penetrating trauma. Certain variables such as age, employment, and admitting status were assigned from a patient's last ED visit during the study. The logistic regression model also assigned cumulative values to the following variables: prior ED visits, high use, and ever-being uninsured. In our final adjusted model, covariates considered to confound the relationship between a prior ED visit for injury and severe penetrating trauma included age, gender, insurance status, employment status, high use, and admitting status. Cox proportional hazard models were used to estimate the HR for factors associated with time to severe penetrating trauma after a patient's last ED visit. All statistical comparisons were performed using SAS version 9.4 (SAS Institute, Inc., Cary, NC). All tests were two-sided and $p$ values of less than 0.05 were considered significant during statistical analysis.

\section{Results}

A total of 215,800 patients were included in this study. Descriptive characteristics of all study participants are summarized in Table 1. Patients with ED visits for injury reasons tended to be male and had high rates of unemployment. Most patients in the study population were uninsured (63\%). A total of 224 patients had severe penetrating trauma following an ED visit. These 224 patients accounted for only $7 \%$ of the total 3,322 penetrating trauma patients on the trauma registry during the study period suggesting a low proportion of penetrating trauma patients utilized emergency care preceding 
Table 1: Demographics and clinical characteristics of patients with emergency department (ED) visits to Grady Memorial Hospital from October 2010 to March 2015

\begin{tabular}{|c|c|c|c|}
\hline & $\begin{array}{l}\text { All patients total } \\
(n=215,800) \\
n(\%)\end{array}$ & $\begin{array}{l}\text { Patients with } \\
\text { penetrating } \\
\text { trauma total ( } n \\
=224) n(\%)\end{array}$ & $\begin{array}{l}\text { Patients without } \\
\text { penetrating } \\
\text { trauma total } \\
(n=215,576) \\
n(\%)\end{array}$ \\
\hline \multicolumn{4}{|l|}{ Gender } \\
\hline Male & $114,683(53)$ & 200 (89) & $114,483(53)$ \\
\hline Female & $100,840(47)$ & $24(11)$ & $100,816(47)$ \\
\hline Declined & $277(<1)$ & - & $277(<1)$ \\
\hline \multicolumn{4}{|l|}{ Age } \\
\hline $15-24$ & $31,506(15)$ & $58(26)$ & $31,448(15)$ \\
\hline $25-34$ & $42,638(20)$ & $88(39)$ & $42,550(20)$ \\
\hline $35-44$ & $33,710(16)$ & $31(14)$ & $33,679(17)$ \\
\hline $45-54$ & 37,164 (17) & $25(11)$ & $37,139(17)$ \\
\hline $55-64$ & $27,602(13)$ & $16(7)$ & $27,856(13)$ \\
\hline$>65$ & $17,561(8)$ & $6(3)$ & $17,555(8)$ \\
\hline Unknown & $25,619(11)$ & - & $25,619(11)$ \\
\hline \multicolumn{4}{|l|}{ Employed } \\
\hline Yes & $63,975(30)$ & $36(16)$ & $63,939(30)$ \\
\hline No & $136,643(63)$ & $175(78)$ & $136,468(63)$ \\
\hline Unknown & $15,182(7)$ & $13(6)$ & $15,169(7)$ \\
\hline \multicolumn{4}{|l|}{ Ever insured } \\
\hline Yes & 79,064 (37) & $33(15)$ & 79,031 (37) \\
\hline No & $136,736(63)$ & $191(85)$ & $136,545(63)$ \\
\hline \multicolumn{4}{|l|}{ Admitted } \\
\hline Yes & $33,089(15)$ & $17(8)$ & $33,072(15)$ \\
\hline No & $182,711(85)$ & 207 (92) & $182,504(85)$ \\
\hline \multicolumn{4}{|c|}{ High ED utilization } \\
\hline Yes & $25,762(12)$ & $39(17)$ & $25,723(12)$ \\
\hline No & $187,362(88)$ & $185(83)$ & $187,177(88)$ \\
\hline \multicolumn{4}{|c|}{ Previous ED visit for injury } \\
\hline Yes & $63,134(29)$ & $106(47)$ & $63,028(29)$ \\
\hline No & $152,666(71)$ & $118(53)$ & $152,548(71)$ \\
\hline
\end{tabular}

their penetrating injury. Table 2 demonstrates that most of these patients were male with a penetrating injury due to a firearm or piercing. The average Injury Severity Score, an anatomical scoring system used for trauma patients, was 8.55 (standard deviation = 9.17). Toxicology results demonstrated that $27 \%$ of the patients tested positive for alcohol or drugs at the time of the trauma event despite a significant number of patients not being tested. About $5 \%$ of these patients died of from their penetrating trauma injuries.

Bivariate analysis demonstrated that patients with a prior ED visit for injury [odds ratio (OR) 2.17, confidence interval (Cl) $1.67-2.83, p<0.0001$ ] had increased odds of penetrating trauma, as shown in Table 3. Male patients had 7.34 times greater odds of penetrating trauma than female patients (OR 7.34, Cl 4.80-11.19, $p<0.0001)$. Patients 35 years old and above had $50 \%$ lower odds of penetrating trauma than patients between 15 years and 35 years of age. Employed patients were also at reduced odds of penetrating trauma (OR 0.44, Cl 0.31-0.63, $p<0.0001$ ) as were patients who had a prior ED visit that required hospital admission (OR 0.45, Cl 0.28-0.74, $p=0.0017)$. The odds of penetrating trauma for patients with a history of being uninsured was 3.35 times higher than patients with

Table 2: Demographics and clinical characteristics of 224 patients with severe penetrating trauma and prior emergency department visits at Grady Memorial Hospital from October 2010 to March 2015

\begin{tabular}{|c|c|c|c|}
\hline & $n(\%)$ & & $n(\%)$ \\
\hline Gender & \multicolumn{3}{|c|}{ Discharge status } \\
\hline Male & $201(90)$ & Alive & $212(95)$ \\
\hline Female & $23(10)$ & Deceased & $12(5)$ \\
\hline \multicolumn{2}{|c|}{ Alcohol toxicology } & \multicolumn{2}{|c|}{ Type of penetrating injury } \\
\hline Positive & $61(27)$ & Firearm & $130(58)$ \\
\hline Negative & $106(47)$ & Cut/pierce & $45(20)$ \\
\hline Not tested & $57(25)$ & Other & $49(22)$ \\
\hline \multicolumn{2}{|c|}{ Drug toxicology } & $\begin{array}{l}\text { Average ISS } \\
\text { score }\end{array}$ & Mean (SD) \\
\hline Positive & $61(27)$ & & $8.55(9.17)$ \\
\hline Negative & $20(9)$ & & \\
\hline Not tested & $143(64)$ & & \\
\hline
\end{tabular}

Table 3: Results of bivariate and multivariate logistic regression analysis of an emergency department (ED) cohort of patient's risk factors for severe penetrating trauma

\begin{tabular}{|c|c|c|c|c|}
\hline Variables & $\begin{array}{l}\text { Unadjusted OR }(95 \% \mathrm{Cl}) \\
n=215,800\end{array}$ & pvalue & $\begin{array}{l}\text { Adjusted OR }(95 \% \text { Cl) } \\
n=181,515\end{array}$ & $p$ value \\
\hline Male gender ${ }^{a}$ & $7.34(4.81-11.21)$ & $<0.0001^{*}$ & $5.73(3.73-8.81)$ & $<0.0001^{*}$ \\
\hline \multicolumn{5}{|l|}{$\mathrm{Age}^{\mathrm{a}}$} \\
\hline $15-24$ & Reference & & Reference & \\
\hline $25-34$ & $1.12(0.80-1.56)$ & 0.4990 & $1.00(0.70-1.41)$ & 0.9760 \\
\hline $35-44$ & $0.50(0.32-0.77)$ & $0.0020^{*}$ & $0.45(0.28-0.70)$ & $0.0005^{*}$ \\
\hline $45-54$ & $0.37(0.23-0.58)$ & $<0.0001^{*}$ & $0.34(0.21-0.55)$ & $<0.0001^{*}$ \\
\hline $55-64$ & $0.31(0.18-0.55)$ & $<0.0001^{*}$ & $0.32(0.18-0.57)$ & $0.0001^{*}$ \\
\hline$>65$ & $0.19(0.08-0.43)$ & $<0.0001^{*}$ & $0.40(0.17-0.96)$ & $0.0402^{*}$ \\
\hline Employed $^{a}$ & $0.44(0.31-0.63)$ & $<0.0001^{*}$ & $0.49(0.34-0.71)$ & $0.0001^{*}$ \\
\hline Ever uninsured & $3.35(2.31-4.85)$ & $<0.0001^{*}$ & $2.54(1.70-3.80)$ & $<0.0001^{*}$ \\
\hline Admitted & $0.45(0.28-0.74)$ & $0.0017^{*}$ & $0.52(0.31-0.88)$ & $0.0139 *$ \\
\hline High ED utilization & $1.56(1.10-2.20)$ & $0.0122^{*}$ & $1.32(0.92-1.90)$ & 0.1292 \\
\hline Prior ED visit for injury & $2.17(1.67-2.83)$ & $<0.0001^{*}$ & $1.60(1.21-2.11)$ & $0.0010^{*}$ \\
\hline
\end{tabular}

annadjusted calculated with $n=215,523$ for sex $n=192,857$ for age, and $n=200,618$ for employment due to missing values

${ }^{*} p$ values are significantly different $(p<0.05)$ 
a history of insurance (OR 3.35, Cl 2.44-4.85, $p<0.0001$ ). Finally, patients with high ED utilization, defined as four or more ED visits prior to outcome or censoring, had increased odds of penetrating trauma (OR 1.56, Cl 1.10-2.20, $p=0.0122$ ).

In a selected multivariate model, after adjusting for the covariates of age, sex, employment status, insurance status, high utilization, and admitting status, a prior ED visit for injury continued to be an independent risk factor for severe penetrating trauma (OR $1.60, \mathrm{Cl} 1.21-2.11, p=0.001)$. A Cox proportional hazard model was designed to estimate the difference in the hazard rates of patients with a last ED visit for injury compared to those without, controlling for confounders. Figure 1 illustrates unadjusted Kaplan-Meier curves of time to severe penetrating trauma by injury diagnosis at last ED visits. Among patients with an injury diagnosis at their last ED visit, the proportion of patients experiencing penetrating trauma was nearly twice as high after 1 year compared with patients without an injury diagnosis. A last ED visit for injury continued to be associated with an elevated HR, even among only patients not admitted to the hospital at the time of their ED visit suggesting less

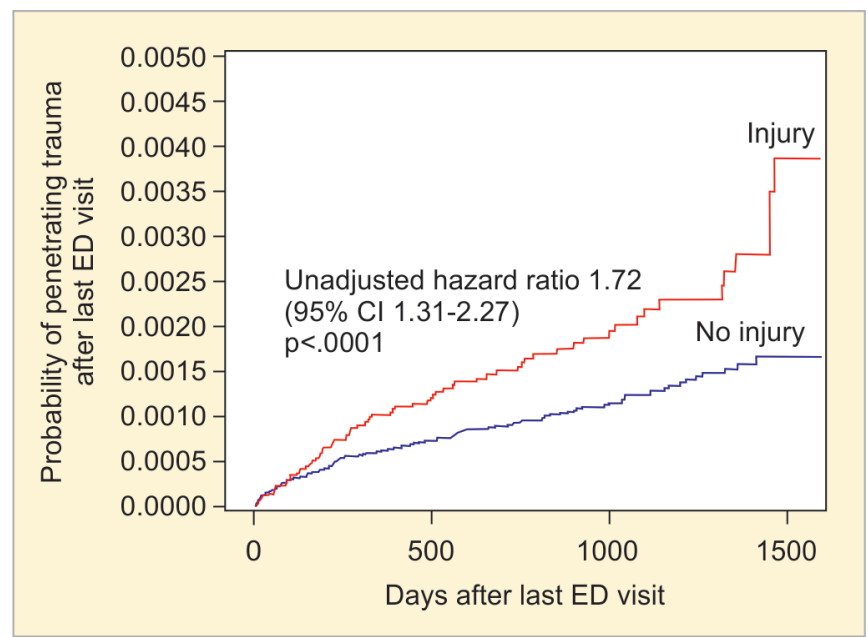

Fig. 1: Unadjusted Kaplan-Meier curve of probability of severe penetrating trauma by last emergency department visit for injury status for all cohort patients, censored at time of study conclusion severe injuries not requiring hospitalization remain a risk factor, as seen in Figure 2. In an adjusted model including, sex, employment status, insurance status, and admitting status, a last ED visit for injury had a hazard rate 1.53 times higher than patients without an injury diagnosis, as shown in Table 4.

\section{Discussion}

With an estimated 40,000 firearm deaths in 2017, severe penetrating trauma continues to be a leading cause of preventable death in the USA. ${ }^{4}$ Previous studies exploring trauma recidivism and its risk factors have largely focused on hospitalized patients. ${ }^{29-31}$ Our study sought to expand this research by identifying risk factors for penetrating trauma among a general ED population. Our analysis found patients presenting to the ED had a significantly increased risk and rate of penetrating trauma after an injury visit. Our other findings were largely consistent with earlier literature on established risk factors for penetrating trauma, namely that being young, male, unemployed, and uninsured served as significant risk factors for

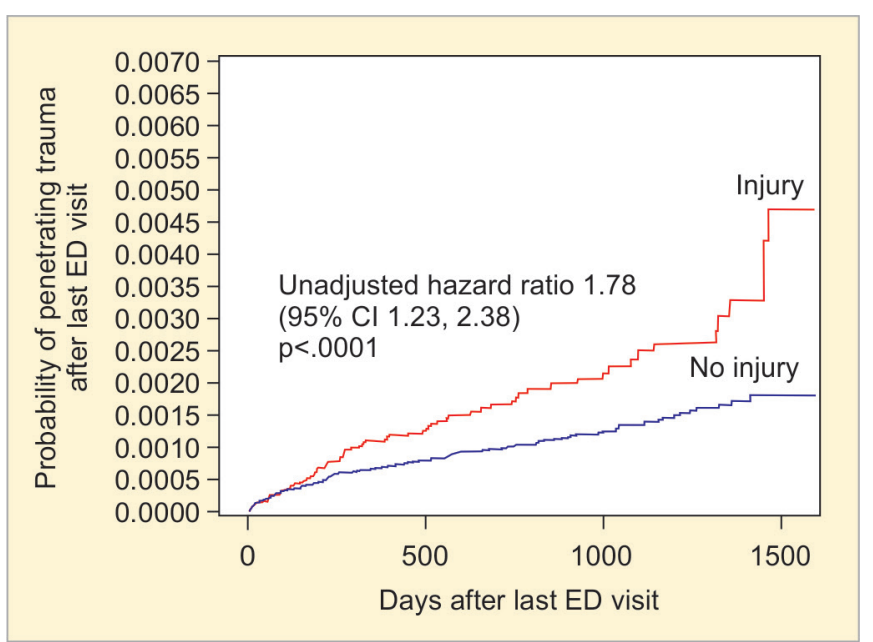

Fig. 2: Unadjusted Kaplan-Meier curve of probability of severe penetrating trauma by last emergency department (ED) visit for injury status among patients not admitted at their last ED visit

Table 4: Hazard ratios for analysis of the association between a patient's last emergency department visit for injury and severe penetrating trauma

\begin{tabular}{|c|c|c|c|c|}
\hline Variables & $\begin{array}{l}\text { Unadjusted HR }(95 \% \mathrm{Cl}) \\
n=215,800\end{array}$ & $p$ value & $\begin{array}{l}\text { Adjusted HR (95\% Cl) } \\
n=181,515\end{array}$ & $p$ value \\
\hline Male $^{a}$ & $7.31(4.78-11.16)$ & $<0.0001$ & $6.01(3.92-9.23)$ & $<0.0001$ \\
\hline \multicolumn{5}{|l|}{ Age } \\
\hline $15-24$ & Reference & - & Reference & - \\
\hline $25-34$ & $1.13(0.81-1.58)$ & 0.460 & $1.03(0.73-1.46)$ & 0.859 \\
\hline $35-44$ & $0.50(0.33-0.78)$ & 0.002 & $0.45(0.29-0.72)$ & 0.0007 \\
\hline $45-54$ & $0.38(0.24-0.60)$ & $<0.0001$ & $0.35(0.21-0.56)$ & $<0.0001$ \\
\hline $55-64$ & $0.34(0.19-0.59)$ & 0.0001 & $0.33(0.19-0.58)$ & 0.0001 \\
\hline$>64$ & $0.20(0.09-0.46)$ & 0.0002 & $0.32(0.13-0.76)$ & 0.010 \\
\hline Employed $^{\mathrm{a}}$ & $0.44(0.31-0.63)$ & $<0.0001$ & $0.45(0.31-0.65)$ & $<0.0001$ \\
\hline Uninsured & $1.86(1.38-2.50)$ & $<0.0001$ & $1.37(0.99-1.89)$ & 0.053 \\
\hline Admitted & $0.46(0.28-0.76)$ & 0.002 & $0.47(0.28-0.79)$ & 0.004 \\
\hline High ED utilization & $2.27(1.60-3.21)$ & $<0.0001$ & $2.73(1.90-3.93)$ & $<0.0001$ \\
\hline Prior ED visit for injury & $1.72(1.31-2.27)$ & $<0.0001$ & $1.43(1.07-1.93)$ & 0.016 \\
\hline
\end{tabular}

annadjusted calculated with $n=215,523$ for sex, $n=192,857$ for age, and $n=200,618$ for employment due to missing values 
penetrating trauma. ${ }^{32}$ Our study also adds to the body of evidence indicating that prior injury is associated with a greater risk of future penetrating trauma and suggests the need for improved injury surveillance in the ED. ${ }^{24,33}$ Currently, it is exceedingly difficult to determine the incidence of violence in our communities due to underreporting and fractured reporting systems. ${ }^{23}$ As such, ED visits for injury, especially those associated with violence, should be an access point for injury surveillance and violence prevention methods.

One method of violence prevention is adopting intensive case management services used by HVIPs. These interventions typically target hospitalized patients and attempt to meet identified psychosocial-economic needs such as housing, employment, medical care, and legal assistance. A number of programs have demonstrated reduced recidivism and cost-effectiveness. ${ }^{34-36}$ However, the intensive nature of these interventions would not be feasible among injured ED patients due to limited resources. As such, certain primary care and ED programs have adopted less intensive methods of violence prevention with some success. ${ }^{27,37}$ For instance, a randomized control trial by Walton et al. demonstrated a significant decrease in violence occurrences after a brief therapeutic intervention provided by a therapist in the ED. ${ }^{38} \mathrm{~A}$ later cost analysis of this trial's intervention estimated the cost ranged from $\$ 3.63$ to $\$ 54.96$ per event averted. ${ }^{39}$ Our study indicates a continued need to adopt, evaluate, and improve ED-based violence prevention programs.

Another critical step in improving the outcomes of injured patients in the ED at high-risk for future trauma is expanding access and referrals to mental healthcare. Victims of violence disproportionately suffer from mental health disorders, such as post-traumatic stress disorder, and are regularly underdiagnosed. ${ }^{40}$ Prior VIPs have demonstrated reduced trauma recidivism with meeting mental health needs. ${ }^{34}$ In order to meet the mental health needs, ED referral methods must consider critical barriers for patients. Our study found injured patients at high risk of future trauma tended to be young and uninsured. For many of these patients, the lack of insurance remains a key barrier to obtaining care. As such, ED referrals should offer accessible community resources and the medical community should continue to lobby for expanded access to mental health services.

There is also a greater role for the medical system to collaborate with other community groups and systems. An innovative program in Cardiff, Wales monitored violent injuries in the ED and later shared anonymized data, such as location, with the relevant local authorities. ${ }^{41}$ This model not only created improved surveillance of community violence, it was also associated with a decrease in violence. ${ }^{42}$ Thus, better surveillance of violence in the ED and a coordinated response with other local agencies could improve community-wide preventive measures for violence.

One limitation of our study is our population was restricted to the patients of a single, large public hospital. This may have contributed to our finding that only a small portion of the ED cohort patients ultimately presented as penetrating trauma registry patients. Kaufman et al. demonstrated many patients with recurrent violent injury access numerous hospitals with $59 \%$ of patients using a different hospital for a second injury. ${ }^{43}$ Thus, it is likely that patients had ED visits and potentially penetrating trauma events outside our study site. In addition, our study relied on passively collected data from ED operations, which provided us a large study sample but at times resulted in poor completion of data fields and limited quality control. In addition, our dataset relied on medical record numbers as a means of connecting patient's ED visits with penetrating trauma events recorded on the trauma registry. This form of matching is likely imperfect and may have failed to identify all relevant patient encounters.

Another limitation of our study is the inability to define the features of the injuries associated with future penetrating trauma, such as intentionality. It is likely that patients with intentional injury due to interpersonal violence are at higher risk of penetrating injury compared to patients with unintentional injury. However, our limited dataset hindered any exploration of intentionality. Still, Haider et al. showed both intentionally and unintentionally injured trauma registry patients had equivalent rates of mortality, although those intentionally injured were at a higher risk of violent death. ${ }^{44}$ In addition, Rowhani-Rahbar et al. demonstrated that unintentional injury, in addition to intentional injury, was associated with future violence-related arrest, suggesting that our use of injury as a broad category likely captures a high-risk group. ${ }^{29}$

This cohort study demonstrates that after adjusting for confounders, a previous ED visit for injury remained a significant risk factor for severe penetrating trauma. Patients with prior ED visits for injury also had a significantly elevated rate of penetrating trauma compared with noninjured ED patients. These findings suggest a need for hospital-based injury surveillance to detect violence and implement evidence-based and cost-effective violence prevention programs. Further research and collaborations on effective violence prevention interventions for ED patients is warranted.

\section{ACKNOWLedgments}

This retrospective cohort study was approved by the Institutional Review Board at Emory University and the Research Oversight Committee at Grady Memorial Hospital.

\section{References}

1. Fowler KA, Dahlberg LL, Haileyesus T, et al. Firearm injuries in the United States. Prev Med 2015;79:5-14. DOI: 10.1016/ j.ypmed.2015.06.002.

2. Kalesan B, Adhikarla C, Pressley JC, et al. The hidden epidemic of firearm injury: increasing firearm injury rates during 2001-2013. Am J Epidemiol 2017;185(7):546-553. DOI: 10.1093/aje/kww147.

3. Jena $A B$, Sun EC, Prasad V. Does the declining lethality of gunshot injuries mask a rising epidemic of gun violence in the United States? J Gen Intern Med 2014;29(7):1065-1069. DOI: 10.1007/s11606-0142779-z.

4. Web-based Injury Statistics Query and Reporting System (WISQARS) [online]. 2005. www.cdc.gov/injury/wisqars. Accessed 2017 April 3.

5. Tracy M, Braga AA, Papachristos AV. The transmission of gun and other weapon-involved violence within social networks. Epidemiol Rev 2016;38(1):70-86. DOI: 10.1093/epirev/mxv009.

6. Wells W, Chermak S. Individual-level risk factors for gun victimization in a sample of probationers. J Interpers Violence 2011;26(11): 2143-2164. DOI: 10.1177/0886260510383022.

7. Haegerich TM, Dahlberg LL, Simon TR, et al. Prevention of injury and violence in the USA. Lancet 2014;384(9937):64-74. DOI: 10.1016/ S0140-6736(14)60074-X.

8. Henrich CC, Brookmeyer KA, Shahar G. Weapon violence in adolescence: parent and school connectedness as protective factors. J Adolesc Health 2005;37(4):306-312. DOI: 10.1016/ j.jadohealth.2005.03.022.

9. Tolan PH, Gorman-Smith D, Henry D, et al. The benefits of booster interventions: evidence from a family-focused prevention program. Prev Sci 2009;10(4):287-297. DOI: 10.1007/s11121-009-0139-8. 
10. Henneberger AK, Varga SM, Moudy A, et al. Family functioning and high risk adolescents' aggressive behavior: examining effects by ethnicity. J Youth Adolesc 2016;45(1):145-155. DOI: 10.1007/s10964014-0222-8.

11. Chong VE, Lee WS, Victorino GP. Neighborhood socioeconomic status is associated with violent reinjury. J Surg Res 2015;199(1):177-182. DOI: 10.1016/j.jss.2015.03.086.

12. Shetgiri $R$, Boots DP, Lin $H$, et al. Predictors of weapon-related behaviors among African American, Latino, and White Youth. J Pediatr 2016;171:277-282. DOI: 10.1016/j.jpeds.2015.12.008.

13. Ruback RB, Shaffer JN, Clark VA. Easy access to firearms: juveniles' risks for violent offending and violent victimization. J Interpers Violence 2011;26(10):2111-2138. DOI: 10.1177/0886260510372948.

14. Papachristos AV, Hureau DM, Braga AA. The Corner and the Crew: the influence of geography and social networks on gang violence. Am Sociol Rev 2013;78(3):417-447. DOI: 10.1177/0003122413486800.

15. Kennedy DM, Piehl AM, Braga AA. Youth violence in Boston: gun markets, serious youth offenders, and a use-reduction strategy. Law Contemp Prob 1996;59(1):147-196. DOI: 10.2307/1192213.

16. Wiebe DJ, Richmond TS, Guo W, et al. Mapping activity patterns to quantify risk of violent assault in urban environments. Epidemiology 2016;27(1):32-41. DOI: 10.1097/EDE.0000000000000395.

17. Lipton $R$, Yang $X$, Braga AA, et al. The geography of violence, alcohol outlets, and drug arrests in Boston. Am J Public Health 2013;103(4):657-664. DOI: 10.2105/AJPH.2012.300927.

18. Beard JH, Morrison CN, Jacoby SF, et al. Quantifying disparities in urban firearm violence by race and place in Philadelphia, Pennsylvania: a cartographic study. Am J Public Health 2017;107(3):371-373. DOI: 10.2105/AJPH.2016.303620.

19. Braga AA, Papachristos AV, Hureau DM. The concentration and stability of gun violence at micro places in Boston, 1980-2008. J Quant Criminol 2010;26(1):33-53. DOI: 10.1007/s10940-009-9082-x.

20. Green B, Horel T, Papachristos AV. Modeling contagion through social networks to explain and predict gunshot violence in Chicago, 2006 to 2014. JAMA Intern Med 2017;177(3):326-333. DOI: 10.1001/ jamainternmed.2016.8245

21. Papachristos AV, Braga AA, Hureau DM. Social networks and the risk of gunshot injury. J Urban Health 2012;89(6):992-1003. DOI: 10.1007/ s11524-012-9703-9.

22. Papachristos AV, Wildeman C. Network exposure and homicide victimization in an African American community. Am J Public Health 2014;104(1):143-150. DOI: 10.2105/AJPH.2013.301441.

23. Sumner SA, Mercy JA, Dahlberg LL, et al. Violence in the United States: status, challenges, and opportunities. JAMA 2015;314(5):478-488. DOI: 10.1001/jama.2015.8371.

24. Cunningham RM, Carter PM, Ranney M, et al. Violent reinjury and mortality among youth seeking emergency department care for assault-related injury: a 2-year prospective cohort study. JAMA Pediatr 2015;169(1):63-70. DOI: 10.1001/jamapediatrics.2014.1900.

25. Smith R, Dobbins S, Evans A, et al. Hospital-based violence intervention: risk reduction resources that are essential for success. J Trauma Acute Care Surg 2013;74(4):976-980; discussion 980-972 10.1097/TA.0b013e31828586c9.

26. Chong VE, Smith R, Garcia A, et al. Hospital-centered violence intervention programs: a cost-effectiveness analysis. Am J Surg 2015;209(4):597-603. DOI: 10.1016/j.amjsurg.2014.11.003.

27. Shibru D, Zahnd E, Becker M, et al. Benefits of a hospital-based peer intervention program for violently injured youth. J Am Coll Surg 2007;205(5):684-689. DOI: 10.1016/j.jamcollsurg.2007.05.029.

28. Bank ANTD. National Trauma Data Standard: Data Dictionary 2014 (2015 Admissions).
29. Rowhani-Rahbar A, Zatzick D, Wang J, et al. Firearm-related hospitalization and risk for subsequent violent injury, death, or crime perpetration: a cohort study. Ann Intern Med 2015;162(7):492-500. DOI: 10.7326/M14-2362.

30. Brooke BS, Efron DT, Chang DC, et al. Patterns and outcomes among penetrating trauma recidivists: it only gets worse. J Trauma 2006;61(1):16-19.; discussion 20 10.1097/01.ta.0000224143. 15498.bb.

31. McCoy AM, Como JJ, Greene G, et al. A novel prospective approach to evaluate trauma recidivism: the concept of the past trauma history. J Trauma Acute Care Surg 2013;75(1):116-121. DOI: 10.1097/ TA.0b013e31829231b7.

32. Vassar MJ, Kizer KW. Hospitalizations for firearm-related injuries. A population-based study of 9562 patients. JAMA 1996;275(22): 1734-1739. DOI: 10.1001/jama.1996.03530460038028.

33. Carter PM, Walton MA, Roehler DR, et al. Firearm violence among high-risk emergency department youth after an assault injury. Pediatrics 2015;135(5):805-815. DOI: 10.1542/peds. 2014-3572.

34. Aboutanos MB, Jordan A, Cohen R, et al. Brief violence interventions with community case management services are effective for high-risk trauma patients. J Trauma 2011;71(1):228-236; discussion 236-227 10.1097/TA.0b013e31821e0c86.

35. Purtle J, Dicker R, Cooper C, et al. Hospital-based violence intervention programs save lives and money. J Trauma Acute Care Surg 2013;75(2):331-333. DOI: 10.1097/TA.0b013e318294f518.

36. Duncan TK, Waxman K, Romero J, et al. Operation PeaceWorks: a community program with the participation of a level II trauma center to decrease gang-related violence. J Trauma Acute Care Surg 2014;76(5):1208-1213. DOI: 10.1097/TA.0000000000000179.

37. Cheng TL, Haynie D, Brenner R, et al. Effectiveness of a mentorimplemented, violence prevention intervention for assault-injured youths presenting to the emergency department: results of a randomized trial. Pediatrics 2008;122(5):938-946. DOI: 10.1542/ peds.2007-2096.

38. Walton MA, Chermack ST, Shope JT, et al. Effects of a brief intervention for reducing violence and alcohol misuse among adolescents: a randomized controlled trial. JAMA 2010;304(5):527-535. DOI: 10.1001/ jama.2010.1066.

39. Sharp AL, Prosser LA, Walton $M$, et al. Cost analysis of youth violence prevention. Pediatrics 2014;133(3):448-453. DOI: 10.1542/peds.20131615.

40. Jaycox LH, Marshall GN, Schell T. Use of mental health services by men injured through community violence. Psychiatr Serv 2004;55(4): 415-420. DOI: 10.1176/appi.ps.55.4.415.

41. Florence C, Shepherd J, Brennan I, et al. Effectiveness of anonymised information sharing and use in health service, police, and local government partnership for preventing violence related injury: experimental study and time series analysis. BMJ 2011;342:d3313. DOI: $10.1136 /$ bmj.d3313.

42. Boyle AA, Snelling K, White L, et al. External validation of the Cardiff model of information sharing to reduce community violence: natural experiment. Emerg Med J 2013;30(12):1020-1023. DOI: 10.1136/ emermed-2012-201898.

43. Kaufman E, Rising K, Wiebe DJ, et al. Recurrent violent injury: magnitude, risk factors, and opportunities for intervention from a statewide analysis. Am J Emerg Med 2016;34(9):1823-1830. DOI: 10.1016/j.ajem.2016.06.051.

44. Haider $\mathrm{AH}$, Young JH, Kisat $\mathrm{M}$, et al. Association between intentional injury and long-term survival after trauma. Ann Surg 2014;259(5): 985-992. DOI: 10.1097/SLA.0000000000000486. 